\title{
Recommendations by the gynecologic endoscopy working group of the german society of obstetrics and gynecology for the advancement of training and education in minimal-access surgery
}

\author{
Rudy Leon De Wilde · Jürgen Hucke • \\ Klaus Kolmorgen $\cdot$ Hans Tinneberg
}

Received: 19 August 2010/Accepted: 13 December 2010/Published online: 12 January 2011

(C) The Author(s) 2011. This article is published with open access at Springerlink.com

Keywords Gynecologic endoscopy · Training and education $\cdot$ Minimal-access surgery $\cdot$ Minimal-invasive surgery $\cdot$ Endoscopic minimal-access operative techniques

\section{Introduction}

Endoscopic minimal-access operative techniques have gained increasing significance in gynecology so that the most gynecological operations in health centers and clinics are now performed via an endoscopic approach: Endoscopy has proven beneficial for patients by reducing morbidity rates, reducing postoperative pain symptoms and shortening hospital stay.

The German healthcare system is undergoing a process of change with increasing integration of ambulatory and inpatient care and a fundamental reform of the DRG-based hospital financing system. Economic restructuring of the healthcare system through personnel and time cutbacks in conjunction with increasing sub-specialization has clearly had a negative impact on the quality of medical training received by the next generation of young doctors. In particular, for specialist surgical areas the average training clinic

R. L. De Wilde $(\bowtie) \cdot$ K. Kolmorgen

Department of Obstetrics and Gynaecology,

Pius Clinic, Georgstr. 12, 26121 Oldenburg, Germany

e-mail: rudy-leon.dewilde@pius-hospital.de

J. Hucke

Department of Obstetrics and Gynaecology,

Bethesda Hospital, Hainstr. 35, 42109 Wuppertal, Germany

H. Tinneberg

Department of Obstetrics and Gynaecology,

Justus-Liebig-University, Klinikstraße 32,

35392 Giessen, Germany has insufficient time or capacity to adequately teach surgical techniques, including minimal-access surgery. Unfortunately, this undesirable development lowers the standard of the surgical techniques required to become a specialist.

The German Gynecologic Endoscopy Working Group (AGE) wish to redress this situation by offering young doctors the opportunity to participate in a structured training plan and a step-by-step guide to endoscopic minimal-access surgery. AGE will name endoscopic training centers throughout Germany-according to the pre-defined criteria-which will offer courses and the opportunity to attend lectures. Doctors may receive a certified graded qualification from the AGE to determine their knowledge and experience of endoscopy.

This concept was first presented at the second "Forum operative gynecology" conference in November 2005 in Berlin. It was discussed and optimized by the AGE council and accepted at the AGE general meeting on 19 May 2005 by the executive committee, advisory board and members of the general meeting. With this concept, we wish to make a contribution to improving the training of young gynecologists and, in the long term, to lower the amount of avoidable surgical complications in gynecological endoscopy.

The concept is sub-divided into a personal qualification (MIS I-III) and an institutional qualification as approved certified training centers.

\section{Personal qualification (certification minimal-invasive surgery I-II-III, MIS I-III)}

Requirements for certification MIS I

- Attendance and successful completion of an AGE introductory course "Gynecological Endoscopy" in an AGE training center. 
- Proof of performing 20 laparoscopic procedures independently (diagnostic, also in conjunction with minor surgical procedure) and 20 hysteroscopy's (diagnostic) by submitting surgical reports and a signature verifying that procedures were performed independently under supervision.

- AGE membership.

- MIS I is unrestricted, as long as an AGE membership is in existence. MIS 1 expires on termination of AGE membership.

- Processing fee: 50.- $€$.

\section{Requirements for certification MIS II}

- Proof of MIS I.

- Attendance and successful completion of an AGE advanced course "Gynecological Endoscopy" in an AGE training center.

- Proof of performing 200 operative laparoscopic procedures independently and 50 operative hysteroscopy's by submitting surgical reports and a signature verifying that procedures were performed independently, eventually under supervision. Data submitted for MIS I are not applicable.

- Proof of annual attendance of official AGE annual meeting or conference "Forum operative gynecology" or conference certified by AGE. In the case of a first application, proof of attendance of at least two of the cited conferences. In the case of a renewed application, at least four.

- AGE membership.

- Five-year validity period.

- For application after a lapse of 5 years, proof of 300 operative laparoscopies and 75 operative hysteroscopy's are required.

- For a transition period until 31 December 2007, points one and two were not mandatory on application.

- Processing fee: $150 .-€$.

\section{Requirements for certification MIS III}

- Proof of MIS II.

- Registered Gynecologist/Obstetrician.

- Proof of performing at least 800 laparoscopic procedures independently over a period of 5 years, this must include at least four of the following surgical procedures.

- Endoscopic hysterectomy (excluding diagnostic laparoscopic + vaginal hysterectomy), myoma enucleation (excluding pedunculated myomas), lymphadenectomy, resection of rectovaginal endometriosis, suspension surgery, organ-saving extirpation of ovarian tumors (excluding the treatment of functional ovarian cysts), organ-saving treatment of tubal pregnancy.

- Proof of performing at least 100 hysteroscopic interventions independently in the course of 5 years, including at least three different types of surgical procedures: myoma resection, polyp resection, septum dissection, hysteroscopic endometrium ablation, intrauterine adhesiolysis in the case of adhesions $\mathrm{III}^{\circ}-\mathrm{IV}^{\circ}$ according to endoscopic gynecology.

- Proof is to be submitted via blinded surgical reports and signature verifying that data are correct and interventions have been performed as a main surgeon. Operations submitted for MIS I and MIS II are not applicable.

- Attending as an observer for at least ten working days at one or more AGE training centers or being director of a certified AGE training center.

- Proof of attendance of five AGE/FOG conferences, or an AGE-certified continuing medical education event.

- AGE membership.

- Five-year validity period.

- In the case of a renewed application after a lapse of 5 years, proof of 1,000 operative laparoscopies (200 of those can be as assisting surgeon) and 100 operative hysteroscopy's (20 of those as assisting surgeon) is to be submitted.

- For a transition period until 31 December 2007, points one and four were not mandatory on application.

- Processing fee: $300 .-€$.

\section{Institutional qualification (AGE training centre)}

\section{Requirements AGE training centre}

- The director has a MIS II or III qualification.

- At least one "Introductory Course" and one "Advanced course" (course contents listed below) is offered and held every year. At least one course within the approval phase and/or prior to application is appraised by a member of the AGE's training commission, executive board, and past presidents. Travel and accommodation costs will be met by the center.

- Operative laparoscopy and operative hysteroscopy should be in routine use at the institution. At least, 800 endoscopic interventions should be performed per year (mandatory proof). These should include at least four of the listed laparoscopic operations (endoscopic hysterectomy (excluding diagnostic laparoscopic + vaginal hysterectomy), myoma nucleation (excluding pedunculated myomas), lymphadenectomy, resection of rectovaginal endometriosis, suspension 
surgery, organ-saving extirpation of ovarian tumors (excluding the treatment of functional ovarian cysts), organ-saving treatment of tubal pregnancy as well as three hysteroscopic interventions (myoma resection, polyp resection, septum dissection, endometrium ablation, treatment for synechia $\mathrm{III}^{\circ}-\mathrm{IV}^{\circ}$ ) (mandatory proof).

- Proof of attending as a long-time learning observer by at least two physicians/year at the training and information center for endoscopy.

- Approval is person and clinic dependent. This is terminated should one of these two parameters be discontinued, i.e., if the director moves to another institution, a new application must be submitted and the departing director may not transfer the qualification to another clinic.

- Application: 500.- €.

- Validity: 5 years.

Contents of the introductory course

Duration: at least two full days

\section{Theory of hysteroscopy}

Diagnostic and mechanical-operative, fundamental equipment knowledge, and physiology (pressure-flow regulation, irrigation liquid and $\mathrm{CO}_{2}$ with physiological aspects, advantages and disadvantages, hysteroflator, various types of hysteroscopes, $30^{\circ}$ telescopes), technical performance of hysteroscopy and diagnosis, problems and complications, course of action in the case of complications.

\section{Theory of laparoscopy}

Fundamental equipment knowledge and physiology (telescopes, insufflators, pneumoperitoneum, camera and video systems, instruments, fundamental principles of electro surgery), fundamental principles of techniques (establishing pneumoperitoneum, alternative course of action in the case of difficult situations such as pre-operated sites, dealing with adipose or extremely thin patients, creating a second puncture site, $0^{\circ}$ and $30^{\circ}$ telescopes), procedures for diagnostic laparoscopy, sterilization, straightforward endometriosis, ovarian cysts, tubal pregnancy, salpingectomy, adnexectomy, organ-saving adnexal surgery, risks and complications, including course of action in the case of complications.

\section{Practice}

- Attending an OR program ( $1 / 2$ day).
- Practice with hystero- and pelvitrainer (at least $1 / 2$ day, two participants per trainer, one tutor for maximum of two trainers).

- Course fee only: Minimum 200.- €.

Contents of advanced course

Duration

\section{Theory of hysteroscopy}

Brief revision of diagnostic hysteroscopy, followed by basic principles of equipment technology and physiology of operative hysteroscopy (pressure-flow regulation, Purisol and physiological significance, pump systems, resectoscope (unipolar-bipolar), basic principles of electro surgery, technical implementation of operative hysteroscopy and treatment of polyps, myomas, septa, synechia, endometrium ablation, problems and complications, course of action in the case of complications.

\section{Theory of laparoscopy}

Brief revision of basic principles of equipment technology and physiology, alternative to initial puncture in the case of difficult situations such as pre-operated sites, procedures for operative laparoscopy, myoma enucleation, LAVH, LASH, extensive endometriosis, lymphadenectomy, risks and complications, including course of action in the case of complications.

\section{Practice}

- Attending a OR program (at least $1 / 2$ day).

- Practice with hystero- and pelvitrainer (at least $1 / 2$ day, two participants per trainer, one tutor for maximum of two trainers).

- Course concludes with MC examination, 30 questions, $60 \%$ correct answers required to pass, AGE compiles and obtains examination questions and results.

- Course fees: Minimum 400.- $€$.

\section{Discussion}

To allow the minimal-invasive surgeon to look outside of the own and known medical and educational system, international congresses that are equivalent to the AGE acknowledged symposia, are accepted as an educational credit. This is only the case if the international congress has been certified by the National Educational Board of the 
country that organizes this operating course, symposium or workshop.

Not every surgeon should have a MIS III-certification; only those that are specialized and predominantly performing minimal-invasive surgery should have this expert status. Allowing some "super specialized" experts in minimal-invasive surgery, which are performing only a specialized form of operative therapy, e.g., oncologic surgery, reproductive surgery, prenatal surgery, etc. to obtain MIS III, a separate pathway has been implemented by the Executive Board of the AGE. After special request, the Executive Board of the AGE will evaluate and acknowledge the MIS status of those "super specialists" in endoscopic surgery.

In a third step, specialization will be integrated in view of the European Certification Process of the EBCOG (European Board and College of Obstetrics and Gynecology). The ESGE (European Society of Gynecological Endoscopy) in cooperation with the BSGE (British Society of Gynecological Endoscopy), RCOG (Royal College of Obstetrics and Gynecologists) and the AGE (German Society of Gynecological Endoscopy) has started a European Education and Certification Project acknowledged by the Standing
Committee of the EBCOG. Third degree certification will then be implemented in case of, e.g., minimal-invasive oncologic surgery, reproductive surgery, urogynecology, etc. This framework will become the basis for education and certification of gynecological minimal-invasive surgery in Europe.

Five years after starting the initial certification process concerning the personal qualification of minimal-invasive surgery I-II-III, the institutional certification as a training centre and after the planned implementation of the personal qualification (MIS I) in the residency of obstetrics and gynecology, there will be a revaluation discussing benefit and pitfalls. Furthermore, it will be interesting to see, how many of the 17,000 gynecologists in Germany and the 2,200 gynecological operative units and institutions, will have undergone the certification process.

Conflict of interest We declare that we have no conflict of interest in relation to this article.

Open Access This article is distributed under the terms of the Creative Commons Attribution Noncommercial License which permits any noncommercial use, distribution, and reproduction in any medium, provided the original author(s) and source are credited. 